\title{
O FENÔMENO JURÍDICO COMO POSSIBILIDADE DO PRÓPRIO NO PÚBLICO
}

\author{
DISSERTAÇÃO DE MESTRADO \\ ORIENTADORA: \\ PROFESSORA DOUTORA JEANNETTE ANTONIOS MAMAN
}

UNIVERSIDADE DE SÃO PAULO

FACULDADE DE DIREITO

SÃO PAULO 


\section{O FENÔMENO JURÍDICO COMO POSSIBILIDADE DO PRÓPRIO NO PÚBLICO}

Dissertação de mestrado apresentada ao Departamento de Filosofia e Teoria Geral do Direito da Faculdade de Direito da Universidade de São Paulo, como exigência parcial para a obtenção do título de Mestre em Filosofia do Direito, sob a orientação da Professora Doutora Jeannette Antonios Maman.

UNIVERSIDADE DE SÃO PAULO

FACULDADE DE DIREITO

SÃO PAULO 


\section{RESUMO}

Este trabalho remete seus esforços para uma investigação que indaga a possibilidade de autenticidade do fenômeno jurídico no público. O método, concebido no sentido de caminho, é trilhado a partir da analítica fundamental de Martin Heidegger, e da hermenêutica compreensiva de Hans-Georg Gadamer percebida sob o viés da via fenomenológica de investigação. O jurídico é constitutivo do ser humano existente, Dasein. Desse modo, o trabalho procura discutir o fenômeno jurídico, sua condição de autenticidade, o modo de ser tradicional do ente humano existente e a mundanidade que o constitui, sob a luz da filosofia heideggeriana do ser. Dasein é ontológico, reconhece esta existência e é interrogado quanto a ela. Dasein pode se mostrar como é, em sua autenticidade e propriedade, mas também pode ocultar-se de diversos modos. O impessoal, modo de ser preponderante do Dasein na cotidianidade, promove a dispersão do Dasein em seu ser-no-mundo, mediano e afastado e, determinado pela publicidade, obscurece o Dasein em sua propriedade. Assim considerando uma investigação do contexto em que se deu a emersão da analítica do ser tornou-se essencial. Uma vez lançadas as bases do pensamento heideggeriano e investigada a analítica fundamental, o modo de ser do direito que se conserva e se repete e que é ditado pela publicidade passa a ser questionado e a compreensão da juridicidade do Dasein no mundo circundante público abre possibilidades para o projeto autêntico na preocupação com o social.

Palavras-chave: Filosofia do ser (Filosofia do direito), analítica fundamental, próprioautêntico, impessoal, público-publicidade. 


\begin{abstract}
The present work addresses its efforts on the inquisition of the possibility of authenticity in the legal phenomenon as perceived in the public. The method, conceived as a path, follows Martin Heidegger's fundamental analytics, and Hans-Georg Gadamer's comprehensive hermeneutics perceived phenomenologically. The legal phenomenon constitutes the Being that ex-ists, Dasein. Therefore, this study seeks to discuss the legal phenomenon, its Beingone's-self condition, the everyday Being-with and its constitutive worldhood in the light of Heidegger's philosophy of Being. Dasein is ontological, recognizes this existence and is questioned about it. Dasein can show itself as it is, in its authenticity and constitution, but it can also cloak its appearance in various modes. "The They", the preponderant Dasein mode in its everydayness, promotes dispersion of the Dasein in its being-in-the world, making it detached and, keeps its authenticity obscured by publicity. Thus, it is essential to investigate Heidegger's analytical thoughts in context. Once Heidegger's basic thoughts have been studied and his fundamental analytics have been analized, the way of being of the law, maintained, repeated and dictated by publicity, begins to be questioned and the understanding Dasein's legal phenomenon of the public world provides possibilities for an authentic project in its social concern.
\end{abstract}

Key-words: Philosophy of Being (Philosophy of Law), Fundamental Analysis, properauthentic, The They, public-publicity. 


\section{SUMÁRIO}

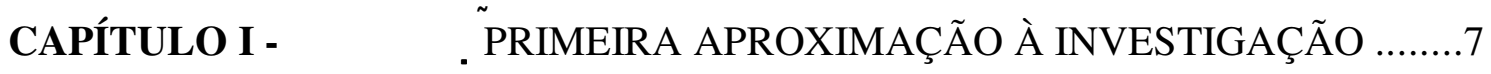

1. Considerações Iniciais: o Problema do Tema e de sua Elucidação ...............................7

1.1. Primeira Visita ao Direito, ao Público e ao Próprio - um Desvio Possível ......10

1.1.1.Breve descrição do direito e concepção preliminar de fenômeno jurídico .......11

1.1.2.As aparências do público .............................................................................12

1.2. Aparentes Limitações da Filosofia Relativamente ao Direito - O Pensar e os Espaços Fundamentais do Tema ………………………………………....20

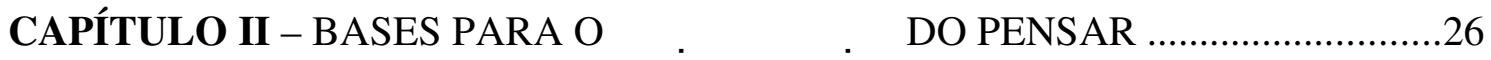

1. Metafísica Tradicional, Humanismo e Bases para a Analítica Fundamental ...........26

2. A Verdade como Desocultação - uma Aproximação à Investigação ..........................35

2.1. O Discurso e as Coisas Mesmas .......................................................................

2.2. A Tecnologia do Pensar e o Enraizamento como Melhor Modo de se Conduzir uma Vida .45

\section{CAPÍTULO III - MOVIMENTO AO REDOR DA TOTALIDADE

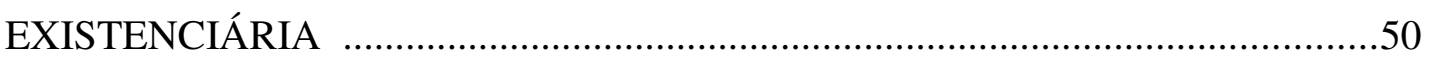

1. A "Percepção" da Tradição Filosófica e os Caminhos efetivos para a Superação ...50

2. Primeiro Mostrar-se do Caminho - A Via Fenomenológica de Investigação ...........51

2.1. Do Fenômeno para a Fenomenologia …………………………………........58

2.2. Do Lógos para a Fenomenologia .......................................................................61

2.3. A Ontologia Fundamental e a Via Fenomenológica de Investigação .................61

3. Dasein e os Modos de Ser do Ser Humano Existente...............................................64

3.1. Mundo e Mundanidade - o Manual e o Intramundano como Constantes na

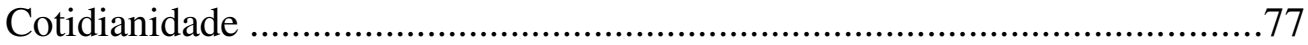

3.1.1.As estruturas da mundanidade e a imediatidade do mundo circundante ..........82

3.2. Os Modos de Ser do Dasein e o seu Modo de ser Tradicional ............................88 
3.2.1. A estrutura do impessoal e o império da publicidade

\section{CAPÍTULO IV - O ACESSO À AUTENTICIDADE COMO POSSIBILIDADE NO} PÚBLICO ENQUANTO ESFORÇO HERMENÊUTICO

1. Publicidade e a Abertura Autêntica do Dasein como Condição de Possibilidade ...99

2. Cura, Autenticidade e Propriedade 104

3. Segunda Evidência de Caminho: o Acesso à Autenticidade pelo Esforço Hermenêutico 108

3.1. O Modo e o Esforço Hermenêutico 111

3.2. Percepção da Proposta Hermenêutica Heideggero-Gadamerana 112

3.3. Acesso à Autenticidade e o Esforço Hermenêutico 119

4. Possibilidade do Fenômeno Jurídico em sua Autenticidade 122

CONCLUSÃO 129

FONTES

BIBLIOGRAFIA 


\section{INTRODUÇÃO}

Nesta investigação indaga-se acerca da possibilidade de autenticidade do fenômeno jurídico na condição pública da convivência humana. A autenticidade, assim entendida como propriedade, o que é mais próprio ao ser, denota o modo de ser essencial do ser humano existente. A existência humana e o ser do direito, que é seu constitutivo, regularmente se mantêm velados na tradição.

As investigações que tradicionalmente a eles se voltam têm por objetivo o modo como tais se dão, e assim considerando, fazem a opção de perquirir os entes, apreciar o que se faz presente, o positivo.

Uma afirmação como a anterior poderia ser presumidamente considerada pretensiosa se não fosse sucedida pela justificativa e também pela explicitação do sentido da investigação, além de sinalizar os caminhos a serem percorridos.

Apresentado um trabalho de filosofia do direito, e obedecendo ao que é exigido pelo senso comum, terá ele suas justificativas. E não poderia ser diferente.

É sabido, percebido e vivenciado que as ditas disciplinas "teóricas" têm tido, no mais das vezes, a aversão de expressiva parcela dos seres sociais. A filosofia, a sociologia, a antropologia e a história, e mais especificamente, essas disciplinas acrescidas do vocábulo direito, quando apresentadas em sala de aula têm em seu conteúdo programático uma vultosa quantidade de horas, reservada apenas para justificar a sua existência, a sua importância e a sua "relação com a prática jurídica".

Ocorre, no entanto, que a justificativa no presente trabalho não pretende seguir o fluxo das chamadas justificativas acadêmicas, eivadas de caráter científico. A motivação, aqui, pretende fazer caminhar por um sentido diferente. É da tradição metafísica a consequência, que não pode ser ignorada, de que a filosofia e seus "desdobramentos" devem ser considerados ciências, sob pena de falta de cientificidade, ou que nem ciências são, e portanto, carecem de utilidade.

Neste trabalho optou-se por seguir outros caminhos que não aqueles das linhas já desde muito desenhadas. Então, investigou-se o ser do modo como está, também indagando sobre as possibilidades deste ser em sua existência naquilo que fora encoberto.

Assim considerando, é de se perquirir inicialmente como se pretende trilhar uma investigação tal qual a presente. A resposta não é a busca de um conceito 
comum. A afirmação que dá ensejo ao título do trabalho abre passagem para um modo de pensar a filosofia, o direito, e pensando, caminhar.

Uma investigação sobre o direito, considerando o já afirmado, dá-se diante de uma investigação sobre o ser. Entes são as coisas individualmente consideradas, bem como a totalidade de tudo o que há. O ser dos entes só pode ser concebido diante do encontro do único ente dotado de existência: o humano. Ao abordar o ser humano existente, está-se perscrutar o sentido do ser que se dá mediante uma compreensão do humano existente em seus modos de ser. Na esteira dos estudos de Martin Heidegger, o professor Aloysio Ferraz Pereira entende que o direito participa do ser.

A reflexão sobre a questão da existência humana e do direito, no caso do presente trabalho, se dá como uma possibilidade que se abre para análise a partir da perspectiva da analítica do ser, ocasião em que se indaga, efetivamente, o fundamento das coisas em si mesmas.

A metódica aqui empreendida é tida, antes de qualquer outra explicação, como de cunho filosófico. Por conseguinte, não poderia oferecer respostas seguras e imediatas nos moldes do estudante de direito, que tem ânsia por soluções rápidas e literalmente concebidas diante do conteúdo da lei.

Tampouco carece da práxis, eis que não tem por referência o caráter polarizado e relacional da teoria e prática. Nesta investigação não se deseja analisar a chamada ciência do direito, ou qualquer outro ramo considerado científico em um sentido tradicional, que tenha por referência a intenção da segurança dos pontos de partida, a clareza, a utilidade, as regras e técnicas da pesquisa. Nesta ocasião não se pretende oferecer respostas seguras, mas ampliar possibilidades.

A investigação que se tenciona promover, a indagação temática que a qualifica e a explicação acima exposta são trilhadas a partir de um caminho que se abre diante da filosofia heideggeriana.

Cabe à ontologia a investigação do ser, mas a opção efetivada tem diante de si um modo de caminhar específico na investigação sobre o ser. Neste caso, as perguntas que se apresentam são pensadas a partir do "como" das coisas mesmas, e são pré-perguntas que se investigam a si próprias.

Segundo as possibilidades filosóficas mencionadas, concebe-se a pesquisa como um caminho que ainda não foi trilhado e que passa a ser preparado durante o caminhar. Tem-se deste modo um caminhar para a pergunta, que já integra a investigação. O ponto de partida da investigação surge então de uma orientação prévia do 
próprio perguntado, que de algum modo se anuncia por uma compreensão vaga e mediana do que é, sem que se saiba como conceituá-lo ou dizer-lhe sobre o seu ser, propriamente.

A investigação se integra no caminho escolhido para análise, ou seja, o método de trabalho, e desconsidera a conotação de que o método vem oferecer um conjunto de ferramentas de trabalho, mas lança luz ao percurso.

Uma investigação como a presente pode ser encarada a partir de perspectivas diversas pertinentes à filosofia, apesar de a pesquisa fazer menção a autores como Aristóteles, Descartes e Kant, ou neokantianos como Habermas; a opção metodológica, como se disse, volta-se para a ontologia fundamental heideggeriana, cujo campo temático é a analítica do Dasein - o ente humano existente -, exposta, sobretudo, em Ser e Tempo, e também a hermenêutica gadameriana desenvolvida especialmente em Verdade e Método.

No presente estudo investiga-se a condição do direito e discute-se o "fenômeno jurídico como possibilidade do próprio no público", vale dizer, pretende-se analisar a condição do que é público para que se reflita sobre possibilidade de o fenômeno se mostrar em sua propriedade. Ocorre que, para fazê-lo, existe uma opção metódica que também é heideggeriana. O método fenomenológico de investigação de Martin Heidegger não é entendido como uma técnica a ser aplicada, e não constitui, ao lado da ontologia, disciplinas diferentes da filosofia. Ambas constituem a própria filosofia naquilo a que se voltam para estudar. O modo fenomenológico estabelece condições para uma investigação ontológica originária. Sob esse aspecto, indica o caminho para fazer ver e remete à abertura do Dasein e à possibilidade de compreensão de seus modos de ser.

Considerando que o viés é heideggeriano, impõe-se também perceber as condições e a constituição da filosofia de Heidegger, ou seja, como compreender os caminhos por ele desenvolvidos.

Desse modo, a investigação cuida de dois objetivos que se combinam, exigem-se um ao outro e praticamente se confundem: o caminho do pensar algumas noções em Heidegger e de como se pode pensá-las, pensando-as.

Na primeira parte do trabalho volta-se para explicitar o problema do tema e de sua elucidação, expondo o sentido da pergunta originária acerca do direito e de sua relação com o sentido do ser e, do mesmo modo, trilhando o caminho para a pergunta essencial: a existência. Desta maneira, considera-se importante discutir a questão originária que reside no princípio das coisas mesmas. Ainda no capítulo primeiro são lançadas para 
reflexão algumas conotações tradicionais concernentes aos termos contidos no trabalho, ou melhor, reflete-se sobre alguns sentidos do direito e do público, considerando-se o modo como eles têm sido abordados. Discorrer acerca do público e das demais combinações do termo, e ainda de aspectos e caminhos da ontologia tradicional, asseverando que as bases e fundamentos do pensamento heideggeriano indicam outro caminho, pode parecer uma ambiguidade. No entanto, exige-se aprender seu sentido habitual.

$\mathrm{Na}$ parte final do primeiro capítulo procura-se estabelecer os espaços fundamentais para a discussão do tema, de modo que os caminhos que remetem aos sentidos inicialmente abordados são abandonados. Assim considerando, admite-se que o fundamento assume uma nova feição, a exata conotação de que a base consiste em um fundo que não se vê, e que por isto permite que seja investigado. Neste momento o trabalho se volta para a filosofia: como pensar e compreender a questão do ser.

Haja vista o fato de que o modo de ser do direito, do público e do próprio não se faz por esclarecer sem a discussão do sentido do ser e da analítica heideggeriana, e tendo sido estabelecidos os espaços reflexivos para tanto, no segundo capítulo explicita-se o contexto em que tal analítica se apresenta. As investigações iniciais são preparatórias para se conhecer e compreender a analítica heideggeriana e dão conta de um dos objetivos do trabalho: a compreensão de algumas noções heideggerianas.

Nesse contexto aborda-se a condição da metafísica tradicional e das investigações acerca do sentido do ser. Heidegger, ao desenvolver a analítica fundamental, o faz em um viés que repensa as origens como um acontecimento apropriado. As origens remetem para o sentido do ser e da verdade.

Em seguida, no capítulo segundo promove-se uma inspeção na tradição metafísica, discutindo-se os contornos daquilo que sob a perspectiva humanista foi estabelecido, mantido e reproduzido ao longo dos tempos, e que se desviou do sentido originário que o estabeleceu.

A tradição da filosofia do ser se consolidou em um modo de descrever a essência do ser com base nos entes, tendo por referência interpretações sobre as origens e sobre o próprio sentido do ser, que consideram a verdade como adequação, e que estabelecem limites específicos e condição instrumental à lógica e à linguagem, bem como fundam a dicotomia entre teoria e prática.

Apresentado o contexto para a analítica heideggeriana, inicia-se o terceiro capítulo com a percepção da tradição filosófica e a investigação da mencionada analítica, que servem para iluminar os caminhos do restante da investigação. Na realidade, 
a ontologia heideggeriana é explicitada em seu sentido essencial, e os termos e aspectos da analítica são discutidos conforme vão aparecendo diante do caminho.

O método fenomenológico de investigação é apresentado durante a discussão sobre o sentido de método, da explicitação da conotação utilizada pelo trabalho e da investigação do sentido de fenômeno. Uma vez demonstrados os modos em que os fenômenos se mostram, o caminho segue em direção ao Dasein. Nesta ocasião, a condição essencial de ente humano existente é analisada a partir da fenomenologia heideggeriana, de tal modo que a investigação trilhe os aspectos do ser humano que, mesmo reais, se afastem da investigação ontológica referente ao sentido do ser.

Considerando que Dasein é sendo, e o é de diversos modos, ainda no capítulo terceiro promove-se uma análise da constituição ontológica do Dasein, vale dizer, analisa-se a condição do mundo e da mundanidade do Dasein e de seus modos de ser.

Avaliadas as noções heideggerianas básicas, estabelecidos os sentidos do ser e as estruturas do Dasein, no caminho apresentam-se então as condições para a investigação do fenômeno jurídico como possibilidade do próprio no público, percorrendo a analítica da existencialidade.

É a partir da mundanidade, do mundo público que lhe é mais próximo e dos modos de ser do Dasein que tem início o mostrar-se do Dasein - e do direito - em sua propriedade, bem como o manifestar-se do impessoal e da publicidade que lhe são constitutivos. O movimento da existência do Dasein o direciona a um estado de decaimento que precisa ser investigado, e que faz ver a condição pública dessa existência tomada pela publicidade do impessoal.

Uma vez explorada a estrutura da publicidade e lançada para discussão a possibilidade de um mostrar-se próprio do Dasein, na pesquisa direciona-se no sentido de considerar o modo de acesso a essa propriedade.

Dessa maneira, a investigação ingressa no pensamento trilhado por HansGeorg Gadamer, na esteira do método fenomenológico de investigação que se põe à disposição da hermenêutica porque dela é característico. A hermenêutica gadameroheideggeriana é então discutida em seus aspectos principais, servindo de caminho para o mostrar-se do Dasein e do Direito como possibilidade autêntica no público.

Termos como investigação, autenticidade, fenômeno jurídico, impessoalidade, público e próprio são enfrentados ao longo do trabalho, e do mesmo modo a terminologia cunhada por Heidegger. 
Como se vê, a presente empreitada não percorre os caminhos tradicionais dos métodos disponíveis e da investigação do público trilhada pela chamada filosofia política. Heidegger libera-se dessa tradição e percorre os caminhos da filosofia. Dentre as diversas possibilidades existentes, este trabalho fez esta opção.

Como se viu, o objetivo da investigação é discutir a possibilidade do fenômeno jurídico como modo de ser autêntico do Dasein na mundanidade. A investigação, a despeito do caminho que se mostra, privilegia o pensamento heideggeriano e, portanto, a analítica do Dasein, do mundo e da publicidade.

A discussão da ontologia clássica - a partir da via fenomenológica de investigação e da hermenêutica compreensiva - contribui para uma abordagem jusfilosófica renovadora e uma crítica histórica e sociológica, todas a partir de uma reflexão inicial integralmente filosófica.

Tratar o impessoal e a publicidade não evidencia, apenas, a discussão daquelas questões (latentes e manifestas) de um campo específico de estudo, mas cuida da essencialização da linguagem e de possibilitar que se pense a verdade na coexistência do ser. 


\section{CONCLUSÃO}

O presente estudo se situou no campo das investigações filosóficas e jusfilosóficas, a partir de um viés sociofilosófico, amparando-se tanto na ontologia fundamental e no método fenomenológico de investigação, revelados por Martin Heidegger, como na hermenêutica compreensiva e no esforço hermenêutico, introduzidos por Hans-Georg Gadamer.

Como se pôde verificar, a investigação se submeteu ao "colete de forças do conceito" $^{\wedge 71}$, mas procurou discutir o fenômeno jurídico, a sua condição de autenticidade, o modo de ser tradicional do ente humano existente e a mundanidade que o constitui sob a luz da filosofia heideggeriana do ser.

Ao fazê-lo, a reflexão fenomênica assumiu a condição essencial do pensamento filosófico, que reside no pensar que compreende o ser enquanto se caminha. "Pensar não é, portanto, exercer uma faculdade da consciência, entendida como sujeito, nem falar é exprimir a atividade e o conteúdo desse exercício. Pensar e falar é articular o destino do $\operatorname{Ser}^{472}$ ".

Heidegger expôs que

(...) a filosofia é uma ontologia fenomenológica e universal que parte da hermenêutica do Dasein, a qual, enquanto analítica da existência, amarra o fio de todo questionamento filosófico no lugar de onde ele brota e para onde retorna ${ }^{473}$.

\footnotetext{
${ }^{471}$ Idem, Lógica, op. cit., p. 116.

${ }^{472}$ Idem, Sôbre o Humanismo ou Carta sobre o Humanismo, op. cit., p. 15.

${ }^{473}$ Idem, Ser e Tempo, Parte I, op. cit., p. 69.
} 
A discussão considerou que a essência do ente humano é a sua existência em um sentido não tradicional, e percorreu os caminhos investigativos para retornar às origens do pensamento essencial.

Tornou-se imperioso investigar o contexto em que se deu a discussão heideggeriana acerca da filosofia do ser. Neste sentido, buscou-se explicitar pensamentos e dialogar com a tradição e também com pensadores que trilharam os caminhos da filosofia do ser. Assim considerando, a investigação lançou as bases da metafísica tradicional e percorreu os caminhos para se pensar a analítica heideggeriana. Neste sentido, foi necessário reconstituir originariamente a constituição do ser, mas também interrogá-lo na mesma direção em que caminhou a metafísica tradicional até o seu desvio.

Uma vez lançadas as bases do pensamento heideggeriano, procurou-se discutir a fenomenologia da analítica fundamental que possibilita a investigação do ser, da sua condição de ser-no-mundo-com-o-outro. Como o ser-no-mundo é constitutivo do Dasein, a concepção de mundo deve ser pensada diante das estruturas básicas do Dasein ${ }^{474}$.

Ao fazê-lo, ingressou-se na filosofia do ser, quando surgiu a indagação acerca dos modos de ser do Dasein. Tendo sido abertas as possibilidades de se pensar os modos de ser do Dasein, fica evidenciado aquilo que se mantém na cotidianidade: o impessoal. Os hábitos e convenções da cotidianidade contribuem para um obscurecimento do Dasein em sua abertura.

Num estudo pré-ontológico de mundo, Dasein em sua compreensão do ser "vive" conforme fora lançado, ou melhor, por ele indicado, e tem naquilo que é notório o que lhe é mais próximo, familiar e "próprio", de modo que nada lhe causa estranheza.

O manuseio das coisas na ocupação no mundo circundante, concebido a partir dos entes, remete imediatamente para "o que" das coisas e o "de que" são feitas. O mundo da ocupação é então visto e percebido como o conjunto dos entes existentes ou a totalidade dos entes. A noção tradicional de mundo como totalidade das coisas que circundam Dasein é constituída por este estar lançado não refletido no mundo das coisas que estão à mão, inclusive os outros seres existentes.

Heidegger discute que esse mundo da ocupação não pode ser separado do mundo público em que os outros vivem, eis que Dasein é essencialmente ser-com ${ }^{475}$. É dessa manifestação, compreendida ontologicamente, que nasce a possibilidade de

\footnotetext{
${ }^{474}$ Idem, p. 89.

${ }^{475}$ Idem, p. 113.
} 
autenticidade: compreender o império da publicidade em sua obscuridade para, a partir de sua própria luz, desvelá-lo.

Considerar esse campo das ocupações facticamente no mundo público, a partir da natureza no "mundo do nós", da integração que a coisa tem naquilo "de que" é feita e "de que modo" atua (a partir do Dasein), acessa-se o mundo daquele que usa, como daquele que produz, mas também o mundo do ser, a partir da natureza.

Aquilo que está mais próximo, ainda que tendo a consistência de sombras, mantém os humanos dia a dia prisioneiros. (...) E, uma vez que não reconhecem de forma alguma esta prisão pelo que ela é, eles consideram que este território cotidiano, abaixo da abóboda dos céus, é a arena da experiência e do julgamento que oferece o único critério para todas as coisas e relações e que fixa as únicas regras para a sua disposição e $\operatorname{arranjo}^{476}$.

Afastamento, medianidade e nivelamento são modos de ser do Dasein e, como tais, constituem a publicidade. O impessoal, determinado e constituído pela publicidade, é o Dasein preponderante da cotidianidade. A publicidade, como abertura específica do impessoal, regula a interpretação do Dasein e do mundo, a tudo obscurecendo e deixando familiar e conhecido. Essa consistência do impessoal, em sua abertura, detém uma disposição, compreensão, discurso e interpretação específicos.

O falatório, que não deve ser recebido de forma pejorativa, consiste no modo de ser da compreensão e da interpretação cotidianas. $\mathrm{O}$ discurso pronunciado como linguagem contém a disposição, a compreensão e a interpretação medianas, ou a linguagem que caracteriza o senso comum e que impera em razão do impessoal, estabelecendo uma "consciência pública".

Na abertura cotidiana do Dasein não há compartilhamento, não há abertura no discursado, pelo contrário, o ser desconhece originariamente aquilo de que trata o discurso. Somente se percebe o falatório, ou seja, a compreensão sem apropriação. Não ocorre apropriação do que foi falado nem tampouco compartilhamento. Diante do falatório e do senso comum apenas se recebe de modo indiferente "alguma coisa", que nada exclui e tudo "compreende".

Tudo é passado adiante no campo da repetição nivelada e mediana do ser. Assim considerando, percebe-se que o discurso se perdeu ou não acessou sua constituição

${ }^{476}$ Idem. A Doutrina de Platão sobre a Verdade. Trad. Jeannette Antonios Maman. In: Revista da Faculdade de Direito/Universidade de São Paulo, v. 100, 2005. pp. 335-360, p. 341. 
originária. Esse falatório contribui para a publicidade e para um estado de interpretação pública que se sintoniza com o modo com que Dasein é tocado pelo mundo: de modo impessoal.

Neste contexto da cotidianidade Dasein se situa aparentemente aberto, porque público, e nesta aparência acredita-se no poder-ser. Este poder-ser, como se vê, é inautêntico, porquanto, na verdade, é prescrito pelo impessoal. Publicamente a aparência é de composição que incentiva a convivência sem fundo, decaída do Dasein. Decaído existencialmente, Dasein não deixa de "ser", tampouco se perde totalmente, apenas nele prepondera um modo de ser.

Os constitutivos da impessoalidade, como modos de ser, e os modos de compreensão, discurso e interpretação estabelecem, sendo possibilitados pelo próprio Dasein, que assim por eles é mantido. Dasein, como ser-no-mundo, mas na ditadura do impessoal, vê-se pela publicidade familiarizado com o "mundo" das ocupações, e com estas se sente próximo em sua facticidade.

Nesse contexto Dasein é sempre considerado em razão da coisa de que se ocupa ou em que está, o que caracteriza a "realidade" do Dasein no mundo: o levar em conta e perceber os entes e agir como se a eles se assemelhasse, Dasein se substancializa.

Ao perceber-se nessa condição, Dasein pode promover uma ruptura, um olhar diferenciado para aquilo que é habitual, corrente e ordinário. Percebendo o habitual e corrente, Dasein já promove um desocultar, e inserir-se novamente nesse habitual, com outro olhar, já promove um ocultar e desocultar constantes. Neste caso, Dasein reconhece o comum, mas a ele não associa o real ou essencial das coisas mesmas.

Dasein pode se perceber em sua estrutura fundamental, como ser-nomundo-com-o-outro, e assim entender a própria mundanidade. Amplia-se para a circunvisão, para a possibilidade da mundanidade do mundo em geral. Assim o mundo circundante público, em que já se tem uma preocupação, também está à mão em decorrência do mundo circundante mais próximo da ocupação comum.

Neste estar à mão, na convivência, "cada um é como o outro", dissolvendo o Dasein que, sem surpresas, deixa a possibilidade de ser si mesmo, determina-se pelo impessoal, dissolve o modo de ser do Dasein e "prescreve o modo de ser da cotidianidade". Com efeito, na cotidianidade, o estar-lançado do Dasein tem uma constituição específica.

Como cura, Dasein percebe-se como um ser-no-mundo-com-os-outros e em ocupação. A cura se opera ao si-mesmo, como modo de ser no mundo. Daí que a cura 
vem para ultrapassar o impessoal, modo de ser preponderante. Isto se dá na medida em que Dasein compreende esse si-mesmo e o faz pela abertura e disposição na consciência fora de si. "Ser ontológico significa ser um ente ao modo da compreensão do ser"

Esta, novamente, constitui uma abertura do Dasein como ser-no-mundo e não uma voz interior. E, como abertura, Dasein abre a possibilidade de poder-ser a partir do perceber o impessoal e superando a ditadura da publicidade. Neste caso, percebe e analisa o mundo circundante mais próximo em sua conjuntura e passa a ser-com-o-outro, mesmo considerando as ocupações.

Quando o Dasein descobre o mundo e o aproxima de si, quando ele abre para si mesmo seu próprio ser, este descobrimento de "mundo" e esta abertura do Dasein se cumprem e realizam como uma eliminação das obstruções, encobrimentos, obscurecimentos, como um romper das deturpações em que Dasein tranca contra si mesmo $^{478}$.

Trata-se de perceber a totalidade instrumental e o seu modo de ser com ela. Considerando que a injunção se dá prioritariamente nos modos de ser do Dasein, é a partir da autenticidade que é possível abrir-se para a propriedade, mesmo no mundo circundante (mas ampliado) e público do "nós".

O familiarizar-se é constantemente renovado por Dasein, que facticamente percebe-se como ser-com-o-outro no mundo circundante público.

Aquilo que a tradição estabeleceu obscureceu as coisas mesmas. Estas coisas mesmas são vistas como aparecem, e diante disto se tem a noção de realidade.

Uma vez esclarecido o processo de acesso ao modo predominante do ser, desencobriu-se o fenômeno do impessoal, tendo como integrante a publicidade. O mundo público é comumente conduzido pela cotidianidade.

O direito é tradicionalmente percebido como técnica e manuseado como instrumento. Neste modo de ser prioritário propaga o discurso indiferente, sem significância e obscurece o social. Sob o império da publicidade o fenômeno jurídico não se mostra em autenticidade e não compreende sua abertura essencial.

Diante da luz, as coisas mostram-se como são. O perceber a possibilidade de autenticidade elabora a situação hermenêutica, orientando-se para aquilo que aparece na forma visível.

\footnotetext{
${ }^{477}$ PEREIRA, Estado e Direito... op. cit., p. 86.

${ }^{478}$ Idem, Ser e Tempo, op. cit., p. 183.
} 
A compreensão da juridicidade como constitutiva do ser-no-mundo-como-outro, que é fenomênica e hermenêutica, é possibilidade para o rompimento da ditadura da publicidade. O fenômeno jurídico, compreendido como modo de ser-com-o-outro, ultrapassa o tradicional autenticamente e é um modo de poder ser em que a preocupação com o social precede a ocupação. Dasein persevera e libera-se autenticamente ${ }^{479}$, e já remete este mundo público do "nós" à iluminação da abóboda grega que é a experiência pública.

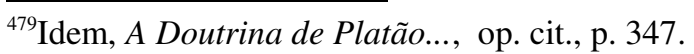




\section{FONTES}

BERGER, Dieter; DROSDOWSKI, Günther; GREBE, Paul; MÜLLER, Wolfgang. Duden

- Die Zweifelsfälle der Deutschen Sprache. Band 5. Mannheim: Dudenverlag, 1974. Idem, Band 9. Mannheim: Dudenverlag, 1974.

BRANDÃO, Junito. Dicionário Mítico-mitológico. Vol. I (A-I). 4ª ed. Petrópolis: Vozes, 2000.

CHANTRAINE, Pierre. Dictionnaire Étymologique de la Langue Grecque - histoire des mots. Vols. 1 e 2. Paris: Klincksieck, 1990.

CUNHA, Celso; CINTRA, Luís F. Lindley. Nova Gramática do Português Contemporâneo. $3^{\mathrm{a}}$ ed. Rio de Janeiro: Nova Fronteira, 2001.

SELIGMAN, Edwin. Encyclopaedia of the Social Sciences. V. 12. New York: The Macmillan Company, 1959.

FREIRE, Antônio. Gramática Grega. 2a ed. Porto: Livraria Apostolado da Imprensa, 1953. GÖTZ, Dieter; HAENSCH, Günther; WELLMANN, Hans. Langenscheidts Großwörterbuch Deutsch als Fremdsprache. 6ª ed. Berlin: Langenscheidt, 2002.

HOEPNER, Luiz; WEBER, Ana Maria C. K. A. Dicionário de Bolso de Português: Português-Alemão, Alemão-Português. Berlin: Langenscheidt, 2001.

HOUAISS, Antônio e VILLAR, Mauro de Salles. Dicionário Houaiss da Língua Portuguesa. Rio de Janeiro: Objetiva, 2001.

LIDDELL, Henry George; SCOUT Robert. Greek-English Lexicon. Oxford: Clarendon, 1968.

LONGMAN Dictionary of English Language and Culture UK: Longman, 1992.

MÉNARD, René. Mitologia Grego-Romana. Vol. 3. Trad. Aldo Della Nina. São Paulo: Opus, 1991.

MITTELSTRA $\beta$, Jürgen. Enzyklopädie Philosophie und Wissenschaftstheorie. Stuttgart: J.

B. Metzler.

MONTANARI, Franco. Vocabulario Della Lengua Greca. Torino: Loescher, 1996.

MURACHCO, Henrique. Língua Grega: visão semântica, lógica, orgânica e funcional.

Vol. 1 - teoria. $2^{\text {a }}$ ed. São Paulo: Discurso Editorial; Petrópolis: Vozes, 2002. 
PEREIRA, Isidro. Dicionário Grego-Português e Português-Grego. Porto: Livraria Apostolado da Imprensa, 1951.

REVISTA Cult. Filosofia do Direito. O que é, o que foi e o que será? N. 112. Ano 10. São Paulo: Bregantini,

TORRINHA, Francisco. Dicionário Latino-Português. $3^{\mathrm{a}}$ ed. Porto: Edições Marânus, 1945.

Dicionário Português-Latino. $2^{\mathrm{a}}$ ed. Porto: Domingos Barreira, 1939.

WAHRIG, Gerhard. Deutsches Wörterbuch. Berlin: Bertelsmann Lexikon, 1977.

Klaus EBNER; Ulrike KADI. (Helmuth VETTER, org.) Wörterbuch der phänomenologischen Begriffe. Hamburg: Felix Meiner Verlag, 2004. 


\section{BIBLIOGRAFIA}

ABBAGNANO, Nicola. Dicionário de Filosofia. $4^{\mathrm{a}}$ ed., 2a . tiragem. São Paulo: Martins Fontes, 2003.

AMIEL, Anne. Hannah Arendt, Política e Acontecimento. Coleção Pensamento e Filosofia. Trad. Sofia Mota. Lisboa: Instituto Piaget, 1996.

ARENDT, Hannah. Compreender: formação, exílio e totalitarismo (ensaios). Trad. Denise Bottman. São Paulo: Companhia das Letras. Belo Horizonte: UFMG, 2008.

A condição humana. Trad. Roberto Raposo. $10^{\mathrm{a}}$ ed. Rio de Janeiro: Forense Universitária, 2004.

Eichmann em Jerusalém - um relato sobre a banalidade do mal. Trad. José

Rubens Siqueira. São Paulo: Companhia das Letras, 1999.

. Entre o Passado e o Futuro. Trad. M. Barbosa de Almeida. $3^{\text {a }}$ ed. São Paulo:

Perspectiva, 1992.

HEIDEGGER, Martin. Correspondências. Trad. Marco Antônio Casanova. Rio de Janeiro: Relume-Dumará, 2000.

Responsabilidade e Julgamento. Trad. Rosaura Eichenberg. São Paulo:

Companhia das Letras, 2004.

ARISTÓTELES. De Anima, livros I, II e III. Trad. Maria Cecília Gomes dos Reis. São Paulo: 34, 2006.

Ética à Nicômaco. Trad. Mário da Gama Kury da edição de I Bekker. 2. a ed.

Brasília: Universidade de Brasília, 1992. . Metafísica. Trad. Edson Bini. Bauru: Edipro, 2006.

Política. Coleção Os Pensadores. São Paulo: Nova Cultural, 2000.

BARKER, Sir Ernest. Teoria Política Grega - Platão e seus predecessores. Trad. Sérgio Fernando Guarischi Bath. Coleção Pensamento Humano. Brasília: Universidade de Brasília: 1978.

BEAUFRET, Jean. Introdução às Filosofias da Existência: de Kierkegaard a Heidegger.

Trad. e notas Salma Tannus Muchail. São Paulo: Duas Cidades, 1976. 
BERCOVICI, Gilberto. Planejamento e políticas públicas: por uma nova compreensão do papel do Estado. In Políticas Públicas: reflexões sobre o conceito jurídico. Org. Maria Paula Dallari Bucci. São Paulo: Saraiva: 2006, pp. 143-161. Soberania e Constituição: Para uma crítica do constitucionalismo. São Paulo: Quartier Latin, 2008.

BORGES, Alice Gonzalez. Interesse Público: um conceito a determinar. In: Revista de Direito Administrativo, n. 205. Rio de Janeiro: Atlas, 1996, pp. 109-116.

BRIGGS, Asa; BURKE, Peter. Uma História Social da Mídia: de Gutenberg à Internet. 2a ed. Revista e ampliada. Trad. Maria Carmelita Pádua Dias. Rio de Janeiro: Jorge Zahar, 2006.

CAMPOS, Alzira Lobo de Arruda. Da Dúvida Cartesiana ao Diálogo Metódico: o declínio da unidisciplinaridade como via metodológica única. In: Revista Tempo e Memória, ano 4, n. 5, julho de 2006.

CAPELLA, Juan Ramón. Fruto Proibido - uma aproximação histórico-teórico ao estudo do Direito e do Estado. Porto Alegre: Livraria do Advogado, 2002.

COSTA JR., Paulo José da. O Direito de Estar Só - tutela penal da intimidade. $4^{\mathrm{a}}$ ed. São Paulo: Revista dos Tribunais, 2007.

DELEUZE, Giles. A Filosofia Crítica de Kant. Lisboa: 70, 1983.

DERRIDA, Jaques. La Desconstrucción en las Fronteras de la Filosofía. Trad. Patrício Peñalvez Gómez. Barcelona: Paidós Ibérica, 1997.

DESCARTES, René. Discurso do Método. Trad. Maria Ermantina Galvão. $2^{\mathrm{a}}$ ed. São Paulo: Martins Fontes, 2003. . Meditações. Trad. Enrico Corvisieri. Coleção Os Pensadores. São Paulo: Nova Cultural, 1996.

FIGUEIREDO, Luís Cláudio. A Questão do Sentido, a Intersubjetividade e as Teorias das Relações de Objeto. In: Revista Brasileira de Psicanálise, vol. 39, n. 4, pp. 79-88, 2006.

FIGAL, Gunter. Martin Heidegger: Fenomenologia da Liberdade. Trad. Marco Antônio Casanova. Rio de Janeiro: Forense Universitária, 2005.

GADAMER, Hans-Georg. Acerca da Disposição Natural do Homem para a Filosofia. In: A Razão na época da ciência. Rio de Janeiro: Tempo Brasileiro, 1983, pp. 78/87. . El Giro Hermenêutico. Trad. Arturo Parada. $2^{\mathrm{a}}$ ed. Madrid: Cátedra, 2001. . Hermenêutica em Retrospectiva - Vol I: Heidegger em retrospectiva. Trad. Marco Antônio Casanova. Petrópolis: Vozes, 2007. 
Hermenêutica como filosofia prática. In: A Razão na época da ciência. Rio de Janeiro: Tempo Brasileiro, 1983, pp. 57/87. . O Problema da Consciência Histórica. Trad. Paulo Cesar Duque Estrada. São Paulo: Fundação Getúlio Vargas.

. Philosophical Hermeneutics. Trad: David E. Linge. Los Angeles: University of California Press.

. Verdade e Método. Volume I. Trad. ênio Paulo Giachini. Petrópolis: Vozes, 2002.

. Idem. Volume II. Trad. Enio Paulo Giachini. Petrópolis: Vozes, 2002.

. Verdad e Método. Vol. I. Trad. Ana Agud Aparício e Rafael de Agapito. 10a ed. Salamanca: Ediciones Sígueme, 2003.

; Idem. Vol. II. Tradução Manuel Olasagasti. $5^{\text {a }}$ ed. Salamanca: Ediciones Sígueme, 2002.

GAOS, José. Introducción a el Ser y el Tiempo de Martin Heidegger. $2^{\mathrm{a}}$ ed. México: Fondo de Cultura Económica, 1996.

GUERRA, François-Xavier; LEMPÉRIÈRE et al. Los Espacios Públicos em Iberoamérica - ambigüedades y problemas. Siglos XVIII-XIX. Centro Francês de Estúdios

Mexicanos y Centroamericanos. México: Fondo de Cultura Econômica, 1998.

HABERMAS, Jürgen. Direito e Democracia - entre facticidade e validade. Vol. I. Trad. Flávio Beno Siebeneichler. $2^{\mathrm{a}}$ ed. Rio de Janeiro: Tempo Brasileiro, 2003.

Mudança Estrutural da Esfera Pública - investigações quanto a uma categoria da sociedade burguesa. Trad. Flávio R. Kothe. 2a . ed. Rio de Janeiro: Tempo Brasileiro, 2003.

Técnica e ciência como ideologia. Trad. Artur Morão. Lisboa: 70, 1968.

HEIDEGGER, Martin. A Caminho da Linguagem. Trad. Márcia Sá Schuback. $4^{\mathrm{a}}$ ed. São

Paulo: Vozes, 2008. . A Doutrina de Platão sobre a Verdade. Trad. Jeannette Antonios Maman. In

Revista da Faculdade de Direito/Universidade de São Paulo. v. 100, 2005. p 335-360 . Being and Time. Trad. John Macquarrie e Edward Robinson. São Francisco: Harper San Francisco/Harper Collins, 1962.

. Carta sobre el Humanismo. Trad. Helena Cortés y Arturo Leyte. Madrid: Alianza Editorial, 2000. 
. El Ser y el Tiempo. Trad. José Gaos. 2a ed. México: Fondo de Cultura

Económica, 2004.

. Ensaios e Conferências. Trad. Emmanuel C. Leão, Gilvan Forgel e Marcia Sá C.

Schuback. $3^{\mathrm{a}}$ ed. São Paulo: Vozes, 2006.

; History of the Concept of Time: Prologómena. Trad. Theodore Sheehan e R. Lilly. Bloomington: Indiana University, 1992.

Que é Isto, a Filosofia: identidade e diferença. Trad. Ernildo Stein. Petrópolis:

Vozes; São Paulo: Livraria Duas Cidades, 2006.

Introdução à Filosofia. São Paulo: Martins Fontes, 2008.

Introducción a la Filosofía. Tradução Manuel Jiménez Redondo. $3^{\mathrm{a}}$ ed. Madri:

Frónesis Cátedra - Universitat de València, 2001.

. Introdução à Metafísica. Trad. Emmanuel Carneiro Leão. Coleção Tempo

Universitário. $3^{\text {a }}$ ed. Rio de Janeiro: Tempo Brasileiro, 1987.

Introduction to Metaphysics. Trad. Gregory Fried e Richard Polt. New Haven:

Yale University, 2000.

Kant y el Problema de la Metafísica. Trad. Gred Ibscher Roth. México: Fondo

de Cultura Económica, 1986.

. La Doctrina de Platón acerca de la Verdad. Trad. de Norberto V. Silvetti.

Cuadernos de Filosofia. Buenos Aires: Instituto de Filosofía de la Universidad de

Buenos Aires, Fasc. VII - ns. 10-11-12, año V-VI, 1952/1953.

La Pregunta por la Técnica. Trad. Eustáquio Barjau. In Conferencías y

artículos. Barcelona: Ediciones del Serbal, 1994, pp. 9-37.

Letter on Humanism. In: KRELL, David Farrell. Martin Heidegger Basic

Writings: from Being and Time (1927) to The Task of Thinking (1964). London and Henley: Routledge \& Kegan Paul, 1978, pp. 189-242.

Lógica: a pergunta pela essência do caminho. Trad. Maria Adelaide Pacheco e

Helga Hoock Quadrado. Lisboa: Fundação Calouste Gulbenkian, 2008.

- Martin Heidegger: Interrogado pelo hebdomadário Der Spiegel - setembro de 1966. Entrevista publicada postumamente em 31 de maio de 1976.

- Nietzsche I. Trad. Marco Antônio Casanova. Rio de Janeiro: Forense

Universitária, 2007.

Nietzsche II. Idem. 
. On the Essence of Truth. In: KRELL, David Farrell. Martin Heidegger Basic

Writings: From Being and Time (1927) to The Task of Thinking (1964). London and Henley: Routledge \& Kegan Paul, 1978, pp. 113-141.

. Ontologia Hermenêutica de la Facticidad. Trad. Jaime Aspiunza. Madrid: Alianza, 1999.

. Parmênides. Trad. Sérgio Mário Wrublevski. Coleção Pensamento Humano.

Petrópolis: Vozes; Bragança Paulista: São Francisco, 2008.

. Que é Isto - A Filosofia? Identidade e diferença. Trad. Ernildo Stein. Coleção

Textos Filosóficos. São Paulo: Vozes/ Duas Cidades, 2006.

. Sein und Zeit. Neunzehnte Auflage. Tübingen: Max Niemeyer Verlag, 2006.

. Ser e Tempo. Parte I. Coleção Pensamento Humano. 13a . ed. Trad. Márcia Sá

Cavalcante Schuback. Petrópolis: Vozes, 2004.

. Idem. Parte II. Coleção Pensamento Humano. Trad. Márcia Sá Cavalcante

Schuback. $10^{\mathrm{a}}$ ed. Idem.

; Idem. Coleção Pensamento Humano. Trad. Márcia Sá Cavalcante Schuback. $3^{\text {a }}$

ed. Petrópolis: Vozes; Bragança Paulista: Universitária São Francisco, 2008.

. Ser y Tiempo. Trad. Jorge Eduardo Rivera. Madri: Trotta, 2003.

. Ser e Verdade - 1. A questão fundamental da filosofia; 2. Da essência da

verdade. Coleção Pensamento Humano. Trad. Emmanuel Carneiro Leão. São Paulo:

Vozes, 2007.

Sôbre o Humanismo ou Carta sobre o Humanismo. Trad. Emmanuel Carneiro

Leão. Rio de Janeiro: Tempo Brasileiro, 1967.

. Sobre o Humanismo - Carta a Jean Beaufret, Paris. In: Coleção Os Pensadores.

Trad., introdução e notas: Ernildo Stein. São Paulo: Nova Cultural, 1979.

. The Origin of the Work of Art. In: KRELL, David Farrell. Martin Heidegger

Basic Writings: From Being and Time (1927) to The Task of Thinking (1964). London and Henley: Routledge \& Kegan Paul, 1978, pp. 144-187.

The Question Concerning Technology. In: KRELL, David Farrell. Martin

Heidegger Basic Writings: From Being and Time (1927) to The Task of Thinking

(1964). London and Henley: Routledge \& Kegan Paul, 1978, pp. 283-317.

Todos Nós... Ninguém: um enfoque fenomenológico do social. Trad. Dulce

Maria Critelli. São Paulo: Moraes, 1981. 
HICKEY, Lance. Kant's Concept of the Transcendental Object. Manuscrito. Revista Internacional de Filosofia. Vol. XXIV, n. 1, abril 2001. Centro de Lógica, Epistemologia e História da Ciência - Unicamp.

INWOOD, Michael. Dicionário Heidegger. Trad. Luísa Buarque de Holanda. Rio de Janeiro: Jorge Zahar, 2002.

JULIÃO, José Nicolao. Sobre a Interpretação Heideggeriana do Eterno Retorno no Pensamento de Nietzsche. V. 3(2) p. 29-46 julho/dez. 1998.

KANT, Immanuel. Resposta à pergunta: O que é 'Esclarecimento'?. In: Textos seletos. Trad. Raimundo Vier e Floriano de Souza Fernandes. Edição Bilingüe, Petrópolis: Vozes, 1974, pp. 100- 117.

. Fundamentação da Metafísica dos Costumes. $7^{\mathrm{a}}$ ed. Lisboa: 70, 1995.

. Crítica da Razão Pura. Versão eletrônica. Trad. J. Rodrigues de Merege.

Créditos da digitalização: Membros do grupo de discussão Acrópolis (Filosofia). Homepage do grupo: http://br.egroups.com/group/acropolis/

KAUFMANN, Arthur; HASSEMER, Winfried (orgs.). Introdução à filosofia do direito e à teoria do direito contemporâneas. Trad. Marcos Keel e Manuel Seca de Oliveira. Revisão científica e coordenação de Antônio Manuel Hespanha. Lisboa: Fundação Calouste Gulbenkian, 2002.

KELSEN, Hans. O que é justiça? A justiça, o direito e a política no espelho da ciência.

Trad. Luís Carlos Borges. 3. a ed. São Paulo: Martins Fontes, 2001.

KRELL, David Farrell. Martin Heidegger Basic Writings: from Being and Time (1927) to the Task of Thinking (1964). London and Henley: Routledge \& Kegan Paul, 1978.

LESSA, Pedro. Estudos de Filosofia do Direito. $2^{\text {a }}$ ed. Campinas: Bookseller, 2002.

LEVINAS, Emmanuel. Martin Heidegger and Ontology. Trad. Committee of Public Safety. The Johns Hopkins University Press, 1996.

LUÑO, Antonio-Enrique Pérez. La Seguridad Jurídica. 2a ed. Barcelona: Ariel, 1994. Teoria del Derecho - una concepción de la experiencia jurídica. $3^{\text {a }}$ ed. Madrid: Tecnos, 2004.

MAC DOWELL, João A. A Gênese da Ontologia Fundamental de Martin Heidegger ensaio de caracterização do modo de pensar de Sein und Zeit. São Paulo: Loyola, 1993.

MAIA, Alexandre da. A dicotomia público x privado com o advento do Estado Social: uma análise crítica à obra de Hannah Arendt. Revista da Faculdade de Direito de Olinda. Olinda, v. 2, ns. 2/3. pp. 81-106, jan./dez. 1998.

MAMAN, Jeannette Antonios. A Via Investigativa da Filosofia do Ser e o Fenômeno 
Jurídico. Revista da Faculdade de Direito/Universidade de São Paulo, v. 99, 2004. pp 477-482.

O Fenômeno Jurídico como Objeto de uma Ontologia Fundamental. Revista da Faculdade de Direito/Universidade de São Paulo, v. 94, 1999, pp. 325-338.

. Fenomenologia Existencial do Direito - Crítica do pensamento jurídico brasileiro. 2a ed. São Paulo: Quartier Latin, 2003.

Língua e Linguagem: os artíficios e a verdade jurídica. Revista da Faculdade de Direito/Universidade de São Paulo, v. 98, 2003, pp. 503-508.

MARKENSON, Roberto. Kant e a Subjetividade Transcendental. Revista de Filosofia da Ufpb. Paraíba, 1992, pp.15-29.

MASCARO, Alysson Leandro. Introdução à Filosofia do Direito: dos modernos aos contemporâneos. $2^{\mathrm{a}}$ ed. São Paulo: Atlas, 2006.

MAZZILLI, Hugo Nigro. O público e o privado. Revista dos Tribunais. São Paulo, v. 84, n. 714, pp. 476-7, abr. 1995.

MERLEAU-PONTY, Maurice. Fenomenologia da Percepção. Trad. Carlos Alberto Ribeiro de Moura. $2^{\text {a }}$ ed. São Paulo: Martins Fontes, 1999.

MORENTE, Manuel García. Fundamentos de Filosofia I - lições preliminares. Trad. e prólogo Guilhermo de la Cruz Coronado. $5^{\text {a }}$ ed. São Paulo: Mestre Jou, 1976.

NIETZSCHE, Friedrich. Genealogia da Moral: Uma polêmica. Trad. Paulo César de Souza. São Paulo: Companhia das Letras, 1998.

OLIVEIRA, Francisco de; PAOLI, Maria Célia (orgs.). Os Sentidos da Democracia: políticas do dissenso e hegemonia global. $2^{\mathrm{a}}$ ed. Núcleo de Estudos dos Direitos da Cidadania. Petrópolis: Vozes; Brasília: NEDIC, 2000.

PAIM, Antônio. Tratado de Ética. Londrina: Humanidades, 2003.

PAISANA, João. Fenomenologia e Hermenêutica. Lisboa: Presença, 1992.

PEREIRA, Aloysio Ferraz. O Direito como Ciência. São Paulo: Revista dos Tribunais, 1980.

Estado e Direito na Perspectiva da Libertação (uma crítica segundo Martin Heidegger). São Paulo: Editora Revista dos Tribunais, 1980.

. História da Filosofia do Direito: das origens a Aristóteles. São Paulo: Revista dos Tribunais, 1980.

. Textos de Filosofia Geral e de Filosofia do Direito. São Paulo: Revista dos Tribunais, 1980. 
PLATÃO. A República. Trad. e notas: Maria Helena da Rocha Pereira. 9a ed. Lisboa: Fundação Calouste Gulbenkian, 2001.

. Teeteto. Trad. Carlos Alberto Nunes. In: Platão: Diálogos. $3^{\mathrm{a}}$ ed. revisada. Belém: Universitária UFPA, 2001.

PRADO JR., Caio. Formação do Brasil Contemporâneo. São Paulo: Brasiliense, 1999.

RAICHELIS, Raquel. Esfera Pública e Conselhos de Assistência Social: caminhos da construção democrática. $4^{\mathrm{a}}$ ed. São Paulo: Cortez, 2007.

Legitimidade Popular e Poder Público. São Paulo: Cortez, 1988.

RIBEIRO, Darcy. O Povo Brasileiro: a formação e o sentido do Brasil. 2a . ed. São Paulo: Companhia das Letras, 1995.

RICOEUR, Paul. Interpretação e Ideologias. Org., trad. e apresentação: Hilton Japiassu. Rio de Janeiro: Francisco Alves, 1977.

ROULAND, Norbert. Nos Confins do Direito. Trad. Maria E. de A. P. Galvão. São Paulo: Martins Fontes, 2003.

SAFRANSKI, Rüdiger. Heidegger: um mestre na Alemanha entre o bem e o mal. São Paulo: Geração, 2000.

SARTRE, Jean-Paul. O Existencialismo é um Humanismo. Coleção os Pensadores. Trad. Vergílio Ferreira. São Paulo: Abril Cultural, 1973.

SCHLEIERMACHER, Friedrich D. E. Hermenêutica, Arte e Técnica da Interpretação. Trad. Celso Reni Braida. 5a ed. Bragança Paulista: Universitária São Francisco, 2006.

SLOTERDIJK, Peter. Regras para o Parque Humano - uma resposta à carta de Heidegger sobre o humanismo. Trad. José Oscar de Almeida Marques. São Paulo: Estação Liberdade, 2003.

SMITH, Daniel. Intensifying Phronesis: Heidegger, Aristotle, and Rhetorical Culture. Pennsylvania State - acesso via VPN-USP - In Projeto Muse, em dez/2008, p. 77-102.

SÓLON, Ari Marcelo. Dever Jurídico e Teoria Realista do Direito. Porto Alegre: Sérgio Antônio Fabris, 2000.

STEIN, Ernildo. Seminário sobre a Verdade - lições preliminares sobre o parágrafo 44 de Sein und Zeit. Petrópolis: Vozes, 1993.

STRECK, Luiz Lenio. Hermenêutica Jurídica e $(m)$ Crise: uma exploração hermenêutica da construção do Direito. $4^{\mathrm{a}}$ ed. Porto Alegre: Livraria do Advogado, 2003.

TELLES, Vera da Silva. Direitos Sociais: afinal do que se trata? Belo Horizonte: UFMG, 2006. 
Espaço Público e Espaço Privado na Constituição do Social: notas sobre o pensamento de Hannah Arendt. In: Tempo Social, revista de Sociologia da Usp. São Paulo, 2(1): 23-48, $1^{\text {o }}$. sem. 1990.

TELLES JÚNIOR, Goffredo da Silva. A Democracia Participativa. Revista da Faculdade de Direito/Universidade de São Paulo, v. 100, 2005, pp. 171-188. . Iniciação na Ciência do Direito. $3^{\mathrm{a}}$ ed. São Paulo: Saraiva, 2006.

VATTIMO, Gianni. Introdução a Heidegger. Trad. João Gama. Rio de Janeiro: 70, 1987.

VILLEY, Michel. Filosofia do Direito. São Paulo: Martins Fontes, 2003.

WARAT, Luís Alberto. O direito e sua linguagem. 2. versão. 2 ${ }^{\mathrm{a}}$ ed. Porto Alegre: Sérgio Antonio Fabris, 1995.

WOLKMER, Antônio Carlos, (org.). Fundamentos de História do Direito. $3^{\mathrm{a}}$ ed. Belo Horizonte: Del Rey, 2005.

ZARADER, Marlène. Heidegger e as Palavras da Origem. Lisboa: Instituto Piaget, 1990. ZINGANO, Marco. Estudos de Ética Antiga. São Paulo: Discurso, 2007.

; Org. Sobre a Metafísica de Aristóteles: textos selecionados. São Paulo: Odysseus Editora, 2005.

; Razão e Sensação em Aristóteles: um ensaio sobre De Anima III, 4-5. Porto Alegre: L\&PM, 1998. 